\title{
Pax4 synergistically acts with Pdx1, Ngn3 and MafA to induce HuMSCs to differentiate into functional pancreatic $\beta$-cells
}

\author{
TING ZHANG $^{1 *}$, HONGWU WANG $^{2 *}$, TIANYOU WANG ${ }^{3}$, CHIJU WEI $^{4}$, HUI JIANG $^{1}$, \\ SHAYI JIANG ${ }^{1}$, JINGWEI YANG ${ }^{1}$, JINGBO SHAO $^{1}$ and LIAN MA MA,6 $^{2,5}$ \\ ${ }^{1}$ Department of Hematology and Oncology, Shanghai Children's Hospital, Shanghai Jiao Tong University, Shanghai 200062; \\ ${ }^{2}$ Department of Pediatrics, The Second Affiliated Hospital of Shantou University Medical College, Shantou, Guangdong 515041; \\ ${ }^{3}$ Hematological Tumor Center, Beijing Children's Hospital Affiliated to Capital Medical University, Beijing 100045; \\ ${ }^{4}$ Multidisciplinary Research Center, Shantou University, Shantou, Guangdong 515063; ${ }^{5}$ Department of Hematology \\ and Oncology, Shenzhen Children's Hospital; ${ }^{6}$ Shenzhen Public Service Platform of Molecular \\ Medicine in Pediatric Hematology and Oncology, Shenzhen, Guangdong 518038, P.R. China
}

Received December 2, 2018; Accepted July 5, 2019

DOI: $10.3892 /$ etm.2019.7854

\begin{abstract}
It has been indicated that the combination of pancreatic and duodenal homeobox 1 (Pdx1), MAF bZIP transcription factor A (MafA) and neurogenin 3 (Ngn3) was able to reprogram various cell types towards pancreatic $\beta$-like cells (p $\beta$ LCs). Paired box 4 (Pax4), a transcription factor, has a key role in regulating the maturation of pancreatic $\beta$-cells (p $\beta C s$ ). In the present study, it was investigated whether Pax4 is able to synergistically act with Pdx1, Ngn3 and MafA to induce human umbilical cord mesenchymal stem cells (HuMSCs) to differentiate into functional $\mathrm{p} \beta \mathrm{Cs}$ in vitro. HuMSCs were isolated, cultured and separately transfected with adenovirus (Ad) expressing enhanced green fluorescence protein, Pax4 (Ad-Pax4), Pdx1+MafA+Ngn3 (Ad-3F) or Ad-Pxa4 + Ad-3F. The expression of $\mathrm{C}$-peptide, insulin and glucagon was detected by immunofluorescence. The transcription of a panel of genes was determined by reverse transcription-quantitative PCR, including glucagon (GCG), insulin (INS), NK6 homeobox 1 (NKX6-1), solute carrier family 2 member 2 (SLC2A2), glucokinase $(\mathrm{GCK})$, proprotein convertase subtilisin/kexin type 1 (PCSK1), neuronal differentiation 1 (NEUROD1), ISL
\end{abstract}

Correspondence to: Dr Jingbo Shao, Department of Hematology and Oncology, Shanghai Children's Hospital, Shanghai Jiao Tong University, 355 Luding Road, Shanghai 200062, P.R. China

E-mail: sjbobo@sina.com

Dr Lian Ma, Department of Hematology and Oncology, Shenzhen Children's Hospital, 7019 Yitian Road, Shenzhen, Guangdong 518038, P.R. China

E-mail:malian8965@sina.com

*Contributed equally

Key words: diabetes, Pax4, human umbilical cord mesenchymal stem cells, cell differentiation, pancreatic $\beta$-cells
LIM homeobox 1 (ISL 1), Pax6 and PCSK type 2 (PCSK2). Insulin secretion stimulated by glucose was determined using ELISA. The results suggested that, compared with Ad-3F alone, cells co-transfected with Ad-Pax4 and Ad-3F expressed higher levels of INS and C-peptide, as well as genes expressed in pancreatic $\beta$ precursor cells, and secreted more insulin in response to high glucose. Furthermore, the expression of GCG in cells transfected with Ad-3F was depressed by Ad-Pax4. The present study demonstrated that Pax4 was able to synergistically act with the transcription factors Pdx1, Ngn3 and MafA to convert HuMSCs to functional p $\beta$ LCs. HuMSCs may be potential seed cells for generating functional $\mathrm{p} \beta \mathrm{LC}$ in the therapy of diabetes.

\section{Introduction}

Diabetes, including type 1 and type 2 diabetes mellitus, is one of the most serious health-threatening diseases worldwide. Transplantation of pancreatic $\beta$-cells $(\mathrm{p} \beta \mathrm{Cs})$, which are responsible for producing insulin, is an effective strategy for the treatment of type 1 and type 2 diabetes (1). However, the availability of $\mathrm{p} \beta \mathrm{Cs}$ is limited and therefore, the production of more $\mathrm{p} \beta \mathrm{Cs}$ is urgently required. The technology of differentiating stem cells into certain cell types holds great promise. Previous studies have focused on inducing embryonic stem cells (ESCs) to differentiate into pancreatic $\beta$-like cells (pßLCs) (2). However, due to several concerns, including ethics, immunological rejection and tumorigenesis potential, the suitability and safety of $\mathrm{p} \beta \mathrm{LC}$ s derived from ESCs remain under debate (3).

Human umbilical cord mesenchymal stem cells (HuMSCs) isolated from human umbilical cord express the surface markers of stem cells, including CD29, CD44, CD59 and CD105 (4,5). Studies from our and other groups have demonstrated that HuMSCs were able to be induced into several types of cell, including osteocytes, chondrocytes, lipocytes, neuron-like cells, cardiomyocyte-like cells and spermatogonium-like cells (6-13). Furthermore, a previous study by 
our group indicated that vector-mediated overexpression of pancreatic and duodenal homeobox 1 (Pdx1), MAF bZIP transcription factor $\mathrm{A}(\mathrm{MafA})$ and neurogenin 3 (Ngn3) in HuMSC significantly promoted the expression of pancreatic genes (13). Therefore, HuMSCs have multi-lineage differentiation potential and may be used for generating $\mathrm{p} \beta \mathrm{LCs}$.

The differentiation of stem cells is tightly regulated by the temporal and spatial expression of transcription factors; in other words, stem cell differentiation is able to be determined by the transcription factors introduced. In addition to stem cells, terminally differentiated cells may be reprogramed to other cell types (14). Numerous cell types have been trans-differentiated into $\mathrm{p} \beta \mathrm{LCs}$ by forcing the expression of three transcription factors, Pdx1, Ngn3 and MafA, which have important roles in promoting the development of the pancreas (15-17). Pax4 is also an indispensable transcription factor for the generation, differentiation, development and survival of $\mathrm{p} \beta \mathrm{Cs}$, evidenced by the observation that Pax4-knockout mice lack a pancreas and die 1-2 days after birth (18). Recent studies highlight the important role of the Pax 4 gene in driving the formation of $\mathrm{p} \beta \mathrm{LCs}$ from other cell types, including pancreatic $\delta$ - and $\alpha$-cells $(19,20)$. Based on these results, it may be proposed that the Pax4 gene synergistically acts with the transcription factors Pdx1, Ngn3 and MafA to promote the development of $\mathrm{p} \beta \mathrm{Cs}$. To this end, the present study aimed to determine whether co-transfecting the above-mentioned 4 transcription factors in HuMSC increases the efficiency of $\mathrm{p} \beta \mathrm{LC}$ formation.

In the present study, HuMSCs were cultured and co-transfected with Pdx1, Ngn3, MafA and Pax4, and the function of the resulting $\mathrm{p} \beta \mathrm{LC}$ s was assessed. It was demonstrated that Pax4 synergistically acts with Pdx1, Ngn3 and MafA to enhance the differentiation of HuMSCs to $\mathrm{p} \beta \mathrm{LCs}$.

\section{Patients and methods}

Plasmids, human umbilical cord and reagents. Adenovirus plasmid carrying Pdx1, Ngn3 and MafA (Ad-3F) and Pax4 (Ad-Pax4) were kindly provided by Professor Chiju Wei from the Multidisciplinary Research Center of Shantou University (Shantou, China) and were originally obtained from the Beta Cell Biology Consortium. Adenovirus plasmid carrying only EGFP was used as a transfection control.

The umbilical cord was obtained from normal full-term pregnant women with cesarean section at the Second Affiliated Hospital of Shantou University (Shantou, China). Maternal donors and their families provided written informed consent and the present study was approved by the ethics committee of Shanghai Children's Hospital (Shanghai, China; ethical approval no. SHMC201707561) and the ethics committee of the Second Affiliated Hospital of Shantou University Medical College (Shantou, China).

H-Dulbecco's modified Eagle's medium (DMEM)/F12 and fetal bovine serum (FBS) were purchased from Gibco (Thermo Fisher Scientific, Inc.); human epidermal growth factor (EGF) and human basic fibroblast growth factor (bFGF) were purchased from Invitrogen (Thermo Fisher Scientific, Inc.); goat anti-human insulin polyclonal antibody (cat. no. sc-7839) was obtained from Santa Cruz Biotechnology; mouse anti-human glucagon monoclonal antibody (cat. no. BM1621) was from Boster Biotechnology; rabbit anti-human C-peptide polyclonal antibody (cat. no. ab82696) was procured from Abcam; cyanine 3 (CY3)-labeled donkey anti-goat IgG (cat. no. A0502) was purchased from Beyotime Institute of Biotechnology; CY3-labeled goat anti-mouse IgG (cat. no. AP181C) was obtained from Sigma-Aldrich (Merck KGaA); and horseradish peroxidase-labeled goat anti-rabbit IgG (cat. no. G-21234) was from Molecular Probes (Thermo Fisher Scientific, Inc.). Primers were synthesized by Nanjing Kingsley Biotechnology Co., Ltd. The kit for reverse transcription (RT; HiScript II Q Select RT SuperMix for qPCR; cat. no. R233-01) and real-time PCR (AceQ qPCR SYBR Green Master Mix; cat. no. Q141-02) was purchased from Vazyme Biotechnology Co. Human insulin ELISA kit (cat. no. EZHI-14K) was purchased from Sigma-Aldrich (Merck KGaA).

HuMSC culture. Umbilical cords of healthy fetuses from full-term pregnancies were obtained and washed with PBS. Amniotic membrane and blood vessels were removed and the remaining tissue was cut into pieces $\left(1.0 \mathrm{~mm}^{3}\right)$. The pieces were cultured in DMEM/F12 containing $10 \% \mathrm{FBS}$, EGF $(5 \mathrm{ng} / \mathrm{ml})$ and Bfgf $(5 \mathrm{ng} / \mathrm{ml})$, and maintained at $37^{\circ} \mathrm{C}$ with $5 \% \mathrm{CO}_{2}$ in a humidified atmosphere. The culture medium was replaced every 2 days. When the cells reached $80-90 \%$ confluence, the cells were digested with $0.25 \%$ trypsin-EDTA (Sigma-Aldrich; Merck KGaA) and passaged.

Cell transfection. HuMSCs were seeded into 12-well plates at a density of $2 \times 10^{5}$ cells/well. After culture for $12 \mathrm{~h}, \mathrm{Ad}-3 \mathrm{~F}$ and/or Ad-Pxa4 (2 $\mu \mathrm{l}$; multiplicity of infection, 10) were added to the respective wells and served as the $3 \mathrm{~F}$, Pax 4 or $3 \mathrm{~F} / \mathrm{Pax} 4$ group. After incubation for $12 \mathrm{~h}$, the cells were washed three times with PBS and cultured in H-DMEM containing 1\% FBS for 4 days. The culture medium was replaced every 2 days.

Immunofluorescence. HuMSCs of the 4th generation were digested and seeded in a 96-well plate. After reaching 60-70\% confluence, the cells were transfected with various Ad plasmids as mentioned above. The cells were fixed with $4 \%$ paraformaldehyde at room temperature for $5 \mathrm{~min}$ and permeabilized with Triton X-100 at room temperature for $30 \mathrm{~min}$. Subsequently, cells were incubated with primary antibodies, including goat anti-human insulin (dilution, 1:100), mouse anti-human glucagon (dilution, 1:100) and rabbit anti-human C-peptide (dilution, $1: 100$ ) at $37^{\circ} \mathrm{C}$ for $2 \mathrm{~h}$. Cells were then incubated with CY3-labeled donkey anti-goat IgG (dilution, 1:1,000), CY3-labeled goat anti-mouse IgG (dilution, 1:1,000) and CY3-labeled goat anti-rabbit IgG (dilution, 1:1,000) at room temperature for $1 \mathrm{~h}$ in the dark. Following staining with DAPI, the fluorescence was examined with a fluorescence microscope (DMi8 Fluorescence Imaging; Leica Microsystems GmbH). The percentage of insulin-, C-peptide- or glucagon-positive cells was calculated as the ratio of positive cells among total cells. The percentage of insulin- or C-peptide-positive cells was used to evaluate the differentiation efficiency of HuMSCs into $\mathrm{p} \beta \mathrm{Cs}$.

RT-quantitative (q)PCR. The total RNA was extracted with a TRIzol kit (Invitrogen; Thermo Fisher Scientific, Inc.). The total RNA was used as template to synthesize complementary (c)DNA by using the commercial RT kit. The expression 

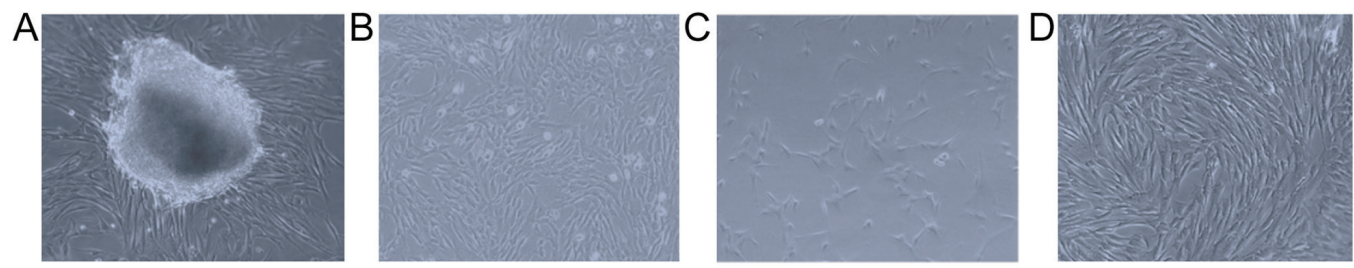

$\mathrm{E}$

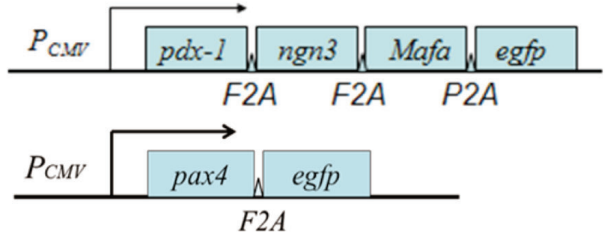

$\mathrm{H}$
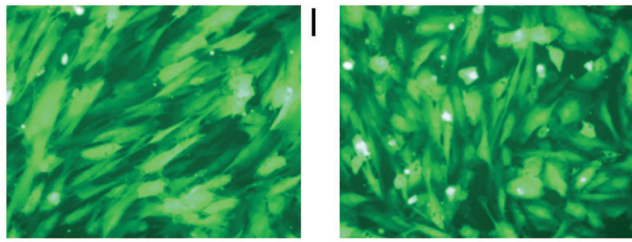
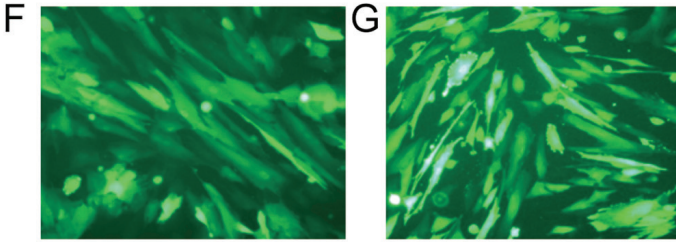

口 PDX1

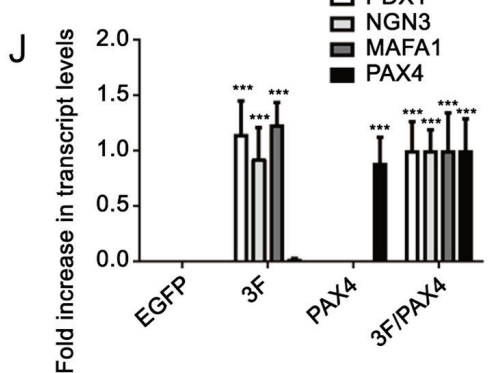

Figure 1. Morphology of cultured HuMSCs and cell transfection. (A) Primary culture of HuMSCs at day 7. Fibroblasts of HuMSCs migrated out of the tissue block. (B-D) Fibroblast-like HuMSCs of the (B) 1st, (C) 3rd and (D) 5th passage (magnification, x100). (E) Diagram of the Ad-3F and Ad-Pax4 constructs. (F-I) EGFP immunofluorescence of HuMSCs transfected with (F) Ad-EGFP, (G) Ad-Pax4, (H) Ad-3F and (I) Ad-Pxa4/Ad-3F at 48 h (magnification, x200). (J) Expression of genes, including PDX1, NGN3, MAFA and PAX4, in HuMSCs transfected with Ad-EGFP, Ad-Pax4, Ad-3F and Ad-Pax4/Ad-3F at 48 h. ${ }^{* * *} \mathrm{P}<0.001$ vs. EGFP. Pdx1, pancreatic and duodenal homeobox 1; MafA, MAF bZIP transcription factor A; Ngn3, neurogenin 3; Pax4, paired box 4; Ad-Pax4, adenovirus expressing Pax4; Ad-3F, Ad-Pdx1/MafA/Ngn3; HuMSCs, human umbilical cord mesenchymal stem cells; $\mathrm{P}_{\mathrm{CmV}}$, cytomegalovirus plasmid; EGFP, enhanced green fluorescence plasmid.

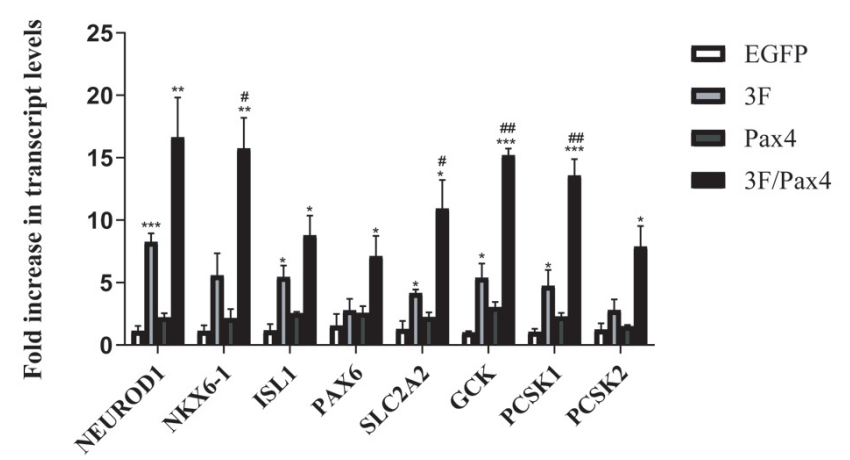

Figure 2. Effect of 3F plasmid in combination with Pax4 overexpression on the expression of genes associated with the differentiation of human umbilical cord mesenchymal stem cells to pancreatic $\beta$-like cells. The genes assessed included NKX6-1, SLC2A2, GCK, PCSK1, NEUROD1, ISL1, PAX6 and PCSK2. Values are expressed as the mean \pm standard deviation $(\mathrm{n}=5) .{ }^{*} \mathrm{P}<0.05,{ }^{* *} \mathrm{P}<0.01,{ }^{* * *} \mathrm{P}<0.001$ vs. EGFP group; ${ }^{\#} \mathrm{P}<0.05,{ }^{\# \#} \mathrm{P}<0.01$ vs. $3 \mathrm{~F}$ group. Groups: EGFP, cells transfected with EGFP plasmid; 3F, cells transfected with Pdx1/MafA/Ngn3 plasmid; Pax4, cells transfected with Pax4 plasmid; 3F/Pax4, cells transfected with Pdx1/MafA/Ngn3 plasmid and Pax4 plasmid. Pdx1, pancreatic and duodenal homeobox 1; MafA, MAF bZIP transcription factor A; Ngn3, neurogenin 3; Pax4, paired box 4; EGFP, enhanced green fluorescence plasmid; GCK, glucokinase; NKx6.1, NK6 homeobox 1; SLC2A2, glucokinase; PCSK1, proprotein convertase subtilisin/kexin type 1; NEUROD1, neuronal differentiation 1; ISL1, ISL LIM homeobox 1; PCSK2, proprotein convertase subtilisin/kexin type 2.

of target genes was detected by qPCR. The thermocycling protocol was as follows: Denaturation at $95^{\circ} \mathrm{C}$ for $1 \mathrm{~min}$; followed by 40 cycles of $95^{\circ} \mathrm{C}$ for $15 \mathrm{sec}, 60^{\circ} \mathrm{C}$ for $15 \mathrm{sec}$ and $72^{\circ} \mathrm{C}$ for $45 \mathrm{sec}$, and then a final elongation at $72^{\circ} \mathrm{C}$ for $10 \mathrm{~min}$. RT-qPCR was performed in a 7300 Real-time PCR instrument (Applied Biosystems; Thermo Fisher Scientific, Inc.) and standardized by the value of $\beta$-actin in the same sample. Data were quantified by using the $2^{-\Delta \Delta \mathrm{Cq}}$ method (21). The sequences of primers were as follows: PDX1 (GenBank ID, NM_000209.4; product length, 193 bp; forward (F)-5'-ATC TCCCCATACGAAGTGCC-3', reverse (R)-5'-CGTGAG CTTTGGTGGATTTCAT-3'; NGN3 (XM_017016280.1; product length, $86 \mathrm{bp}$; F-5'-CTAAGAGCGAGTTGGCAC TGA-3', R-5'-GAGGTTGTGCATTCGATTGCG-3'); MAFA (NM_201589.4; product length, 150 bp; F-5'-GTACAGGAC GTGGACACCAG-3', R-5'-AATCACCGTTCTCCGCTC AA-3'); PAX4 (NM_001366111.1; product length, 127 bp; F-5'-ATACCCGGCAGCAGATTGTG-3', R-5'-AAGACACCT GTGCGGTAGTAA-3'); glucagon (GCG; NM_002054.5; product length, $108 \mathrm{bp}$; F-5'-AGCTGCCTTGTACCAGCA TT-3', R-5'-TGCTCTCTCTTCACCTGCTC-3'); insulin (INS; NM_001291897.1; product length, 130 bp; F-5'-CAATGCCAC GCTTCTGC-3', R-5'-TTCTACACACCCAAGACCCG-3'); neuronal differentiation 1 (NEUROD1; NM_002500.4; product length, 92 bp; F-5'-ATCAGCCCACTCTCGCTG TA-3', R-5'-GCCCCAGGGTTATGAGACTAT-3'); NK6 homeobox 1 (NKX6.1; NM_006168.2; product length, 106 bp; F-5'-CGAGTCCTGCTTCTTCTTGG-3', R-5'-GGG GATGACAGAGAGTCAGG-3'); ISL LIM homeobox 1 (ISL1; NM_002202.3; product length, 108 bp; F-5'-TCA 

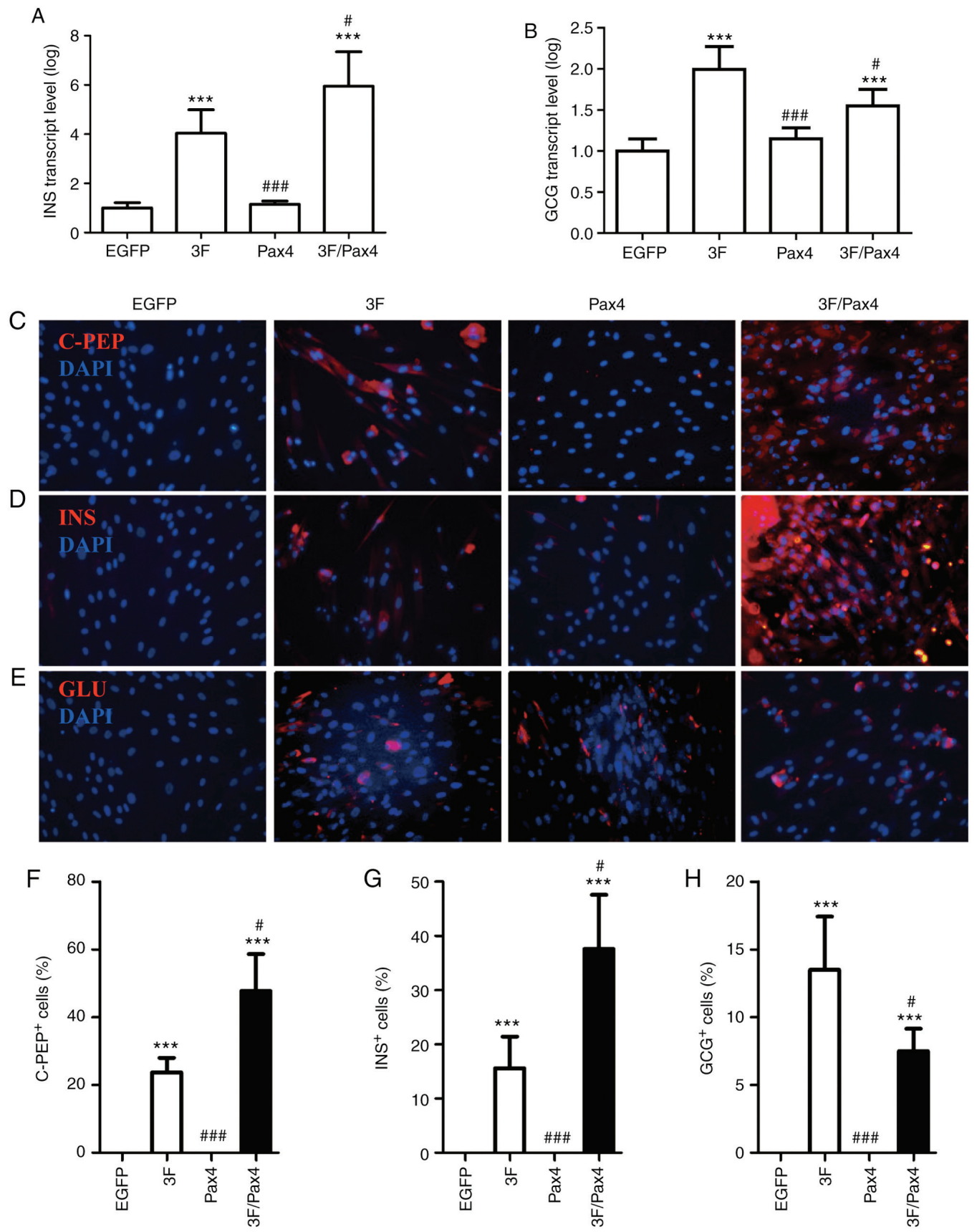

Figure 3. Effect of 3F plasmid in combination with Pax4 overexpression on the expression of C-PEP, INS and glucagon. (A and B) Gene expression of (A) INS and (B) GCG in the different groups compared with the EGFP group. (C-E) Immunofluorescence detection of (C) C-PEP (red), (D) INS and (E) GCG (red) (magnification, x200). (F-H) Quantification of (F) C-PEP- (G) INS- and (H) GCG-positive cells from C-E, respectively. Values are expressed as the mean \pm standard deviation $(\mathrm{n}=5) .{ }^{* * *} \mathrm{P}<0.001$ vs. EGFP group; ${ }^{*} \mathrm{P}<0.05,{ }^{\# \#} \mathrm{P}<0.001$ vs. $3 \mathrm{~F}$ group. Groups: EGFP, cells transfected with EGFP plasmid; $3 \mathrm{~F}$, cells transfected with Pdx1/MafA/Ngn3 plasmid; Pax4, cells transfected with Pax4 plasmid; 3F/Pax4, cells transfected with Pdx1/MafA/Ngn3 plasmid and Pax4 plasmid. Pdx1, pancreatic and duodenal homeobox 1; MafA, MAF bZIP transcription factor A; Ngn3, neurogenin 3; Pax4, paired box 4; EGFP, enhanced green fluorescence plasmid; C-PEP, C-peptide; INS, insulin; GCG, glucagon.

CGA AGTCGTTCTTGCTG-3', R-5'-CATGCTTTGTTA GGGATGGG-3'); PAX6 (NM_001310161.1; product length, 101 bp; F-5'-TCCGTTGGAACTGATGGAGT-3', R-5'-GTT GGTATCCGGGGACTTC-3'); SLC2A2 (NM_001278658.1; product length, 93 bp; F-5'-GACAGTGAAAACCAGGGT CC-3', R-5'-TGTGCCACACTCACACAAGA-3'); glucokinase (GCK; NM_000162.5; product length, 97 bp; F-5'-CCTTCT TCAGGTCCTCCTCC-3', R-5'-ATGCTGGACGACAGA GCC-3'); PCSK1 (NM_000439.5; product length, 101 bp; F-5'-CGGGTCATACTCAGAGGTCC-3', R-5'-CTCTGGCTG
CTGGCATCT-3'); proprotein convertase subtilisin/kexin type 2 (PCSK2; NM_002594.5; product length, 99 bp; F-5'-TTTCGGTCAAATCCTTCCTG-3', R-5'-TGCAAAGGC CAAGAGAAGAC-3'); $\beta$-ACTIN (NM_001101.5; product length, 93 bp; F-5'-GTTGTCGACGACGAGC-3', R-5'-GCA CAGAGCCTCGCCTT-3').

ELISA. Transfected cells were incubated with Krebs-Ringer buffer (KRB) medium containing 2.8 or $20 \mathrm{mM}$ glucose (Beijing Maichen Science and Technology) at $37^{\circ} \mathrm{C}$ for $3 \mathrm{~h}$. The 
KRB medium was collected for detection of secreted insulin. The remaining cells were scraped off in 35\% ethanol solution containing $0.18 \mathrm{M}$ hydrochloric acid. The cells were then homogenized by ultrasound $(20 \mathrm{kHZ}$, ultrasound utilized for $10 \mathrm{sec}$ with $60 \mathrm{sec}$ intervals. The procedure was repeated 6 times) and put under vortex in a shaker $(100$ times $/ \mathrm{min})$ at $4^{\circ} \mathrm{C}$ overnight. The homogenate was centrifuged at $300 \mathrm{xg}$ for $30 \mathrm{~min}$ at $4^{\circ} \mathrm{C}$. The supernatant was collected to determine the intracellular insulin content and insulin secretion was normalized to it. The insulin assay was performed by using the commercial ELISA kit.

Statistical analysis. Values are expressed as the mean \pm standard deviation. Student's t-test was used to determine the statistical significance of differences between two groups, and for more than two groups, one-way analysis of variance followed by a least-significant difference post-hoc test was used. $\mathrm{P}<0.05$ was considered to indicate statistical significance. All data were analyzed by SPSS 20.0 (IBM Corp.).

\section{Results}

Morphology of cultured HuMSCs and cell transfection. After the pieces of umbilical cord tissues had been cultured for 5-7 days, cells that migrated out from the surrounding tissues were fibroblast-like (Fig. 1A). After culture for 10-14 days, the cells reached $80-90 \%$ confluence and were passaged (Fig. 1B). After the second generation, the cells grew rapidly and were subjected to subculture once every 3-5 days. In the 3rd-5th generation, cells had a stable fibroblast-like morphology (Fig. 1C and D), and a previous study by our group demonstrated that these cells highly expressed adult stem cell markers, including CD29, CD44 and CD59 (2). However, after the 10th generation, the cells tended to grow slowly and become wide. Therefore, cells in the 3rd-5th generation were used in the present study. A diagram of the Ad-3F and Ad-Pax4 construct is presented in Fig. 1E. The results of EGFP immunofluorescence revealed that the adenovirus plasmid transfection efficiency was $>80 \%$ (Fig. 1F-I). Furthermore, the results from RT-qPCR suggested that the transfected genes were efficiently expressed in HuMSCs (Fig. 1J).

Effect of Ad-3F in combination with Ad-Pax4 on the differentiation of HuMSCs to p $\beta L C$ s by assessing crucial genes associated with differentiation. To investigate whether Ad-Pax4 further promotes the differentiation of Ad-3F-transfected HuMSCs to $\mathrm{p} \beta \mathrm{LCs}$, a panel of genes involved in converting the progenitors of $\mathrm{p} \beta \mathrm{Cs}$ into $\mathrm{p} \beta \mathrm{Cs}$ were detected, including NKX6-1, SLC2A2, GCK, PCSK1, NEUROD1, ISL1, PAX6 and PCSK2. The results demonstrated that compared with that in the control group, transfection with Ad-Pax4 alone had little effect on the expression of the above-mentioned genes, while transfection with Ad-3F or Ad-3F/Pax-4 increased the expression of these genes. Of note, Ad-Pax4 further promoted the expression of NKX6-1, SLC2A2, GCK and PCSK1 in Ad-3F-transfected cells (Fig. 2).

Effect of Ad-3F in combination with Ad-Pax4 on the expression of C-peptide, insulin and glucagon. To investigate the effect of Ad-3F in combination with Ad-Pax4 on the expression of C-peptide, insulin and glucagon, RT-qPCR and

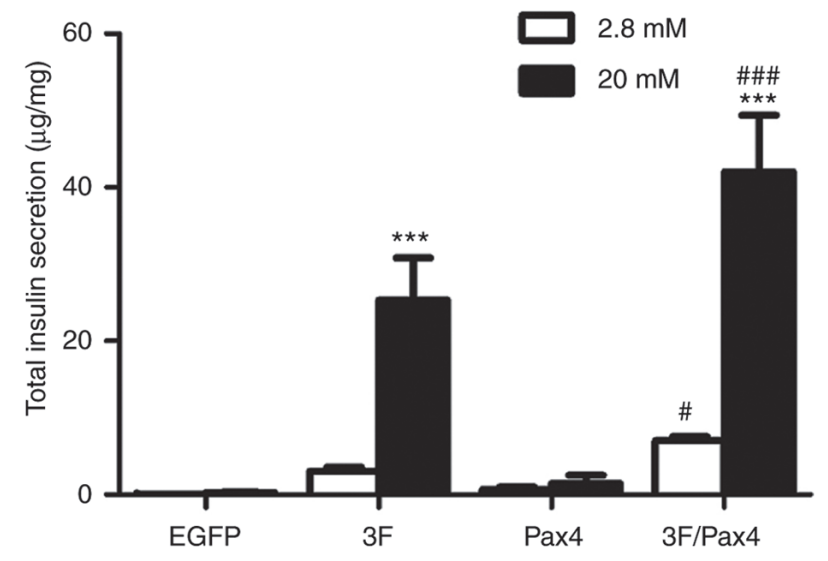

Figure 4. Effect of 3F plasmid in combination with Pax4 overexpression on insulin secretion in response to glucose. Transfected cells were stimulated either with low-glucose or high-glucose, and insulin secretion was determined by ELISA. Experiments were performed 4 days after transduction. Values are expressed as the mean \pm standard deviation $(\mathrm{n}=5) .{ }^{* * * *} \mathrm{P}<0.001$ vs. low-glucose group; ${ }^{\#} \mathrm{P}<0.05,{ }^{\# \#} \mathrm{P}<0.001$ vs. $3 \mathrm{~F}$ group. Groups: EGFP, cells transfected with EGFP plasmid; 3F, cells transfected with Pdx1/MafA/Ngn3 plasmid; Pax4, cells transfected with Pax4 plasmid; 3F/Pax4, cells transfected with $\mathrm{Pdx} 1 / \mathrm{MafA} / \mathrm{Ngn} 3$ plasmid and Pax4 plasmid. Pdx1, pancreatic and duodenal homeobox 1; MafA, MAF bZIP transcription factor A; Ngn3, neurogenin 3; Pax4, paired box 4; EGFP, enhanced green fluorescence plasmid.

immunofluorescence analyses were performed. The RT-qPCR results indicated that compared with that in the control group, the gene expression of INS and GCG was significantly enhanced in the Ad-3F and Ad-3F/Pax-4 group (Fig. 3A and B). Compared with that in the Ad-3F group, the gene expression of INS was significantly increased, while that of GCG was significantly reduced in the Ad-3F/Pax-4 group (Fig. 3A and B). The immunofluorescence results indicated that compared with those in the control group, the glucagon-, insulin- and C-peptide-positive cells were significantly increased in the Ad-3F and Ad-3F/Pax4 groups (Fig. 3B-H). Compared with those in the Ad-3F group, insulin- and C-peptide-positive cells were significantly increased, while glucagon-positive cells were significantly reduced in Ad-3F/Pax4 group (Fig. 3B-H). Furthermore, the differentiation efficiency of HuMSCs co-transfected with Ad-3F and Ad-PAX4 into $\mathrm{p} \beta \mathrm{LCs}$ was $30-40 \%$, as reflected by the insulin- or C-peptide-positive cells (Fig. 3C, D, F and G).

Effect of Ad-3F in combination with Ad-Pax4 on glucose-stimulated insulin secretion (GSIS). To investigate the effect of Ad-3F in combination with Ad-Pax4 on GSIS, the cells were stimulated with low $(2.8 \mathrm{mM})$ and high $(20 \mathrm{mM})$ glucose. The results suggested that compared with low glucose, the insulin secretion in cells stimulated with high glucose was significantly increased in the Ad-3F and Ad-3F/Pax4 groups (Fig. 4). Compared with that in the $3 \mathrm{~F}$ group, the insulin secretion was significantly increased in the Ad-3F/Pax-4 group (Fig. 4).

\section{Discussion}

In the present study, cultured HuMSCs were successfully differentiated into functional $\mathrm{p} \beta \mathrm{LCs}$ by introducing 4 transcription factors, Pdx1, Ngn3, MafA and Pax4. The results demonstrated that, compared to Ad-3F-transfected cells, those co-transfected with Ad-Pxa4 and Ad-3F expressed higher 
levels of insulin, c-peptide and genes expressed in pancreatic $\beta$-precursor cells, and secreted more insulin in response to glucose. Furthermore, Ad-Pax4 significantly decreased the expression of glucagon in Ad-3F-transfected HuMSC.

The embryonic pancreas development is regulated by the interactions of numerous signaling pathways that contribute to the proper initiation of the sequential expression of transcription factors (22-25). Several transcription factors have been demonstrated to be necessary for the development of a functional pancreas, including Pdx1, Ngn3 and MafA. Pdx1, a member of the ParaHox protein family, has an important role in driving the formation of the pancreatic bud $(26,27)$. Ngn3, a member of the basic helix-loop-helix transcription factors, is required for the formation of a common precursor for the four pancreatic endocrine cell types. MafA, an eye-specific member of the Maf family, has been demonstrated to have a vital role in regulating insulin gene expression (28-30). It has been previously reported that the 3 transcription factors combined were able to reprogram other cell types into functional p $\beta \mathrm{LCs}$ (17). Pax4 has been demonstrated to have a critical role in converting the pancreatic $\beta$-precursors to pancreatic endocrine cell types (31). In a previous study, exocrine tissue was effectively converted to islet-like cells by using a cocktail of transcription factors, Pdx1, Ngn3, MafA and Pax4 (32). Consistent with that, the present study indicated that overexpression of Pax4 increased the expression of INS, C-PEP and genes expressed in pancreatic $\beta$-precursor cells, and enhanced glucose-stimulated insulin secretion (GSIS) in Ad-3F transfected HuMSCs, indicating a synergetic effect of Pax4 and Pdx1/Ngn3/MafA on converting HuMSCs to functional $\mathrm{p} \beta \mathrm{LCs}$.

The role of the transcriptional factors Ngn3, Pdx1, MafA and Pax4 in controlling the development of a functional pancreas has been well established. Ngn3 facilitates the formation of pancreatic endocrine cells. Pax 4 directs the cell differentiation towards $\mathrm{p} \beta \mathrm{Cs}$. Pdx 1 and MafA are necessary for maintaining mature $\mathrm{p} \beta \mathrm{C}$ function (31). The mechanism of $\mathrm{Pax} 4$ in promoting $\mathrm{p} \beta \mathrm{C}$ formation may rely on its role to suppress aristaless related homeobox genes, and overexpression of Pax4 was sufficient to convert pancreatic $\alpha$-cells to $\beta$-cells $(20,33)$. In the present study, it was indicated that overexpression of Pax4 decreased glucagon expression in HuMSCs transfected with Ad-3F, suggesting that $\mathrm{Pax} 4$ restricts the differentiation of HuMSCs into paCs. However, glucagon-positive cells still existed in HuMSCs co-transfected with Ad-3F and Ad-Pax4.

NKX6-1 has a key role in regulating insulin secretion and $\beta$-cell proliferation (34). Overexpression of NKX6-1 in mature $\beta$-cells enhanced proliferation and GSIS (35). It has been demonstrated that Glu2 was involved in controlling insulin secretion $(36,37)$. GCK, a key regulator of glucose metabolism, is crucial for GSIS and overexpression of GCK in $\beta$-cells restored GSIS in a mouse model of high-fat diet-induced diabetes (38). PCSK1 is necessary for processing pro-insulin (39). In the present study, it was indicated that Pax 4 promoted the expression of all these genes in the Ad-3F-transfected cells. In line with this, overexpression of Pax4 increased GSIS of HuMSCs transfected with Ad-3F. These results indicate that Pax4 synergistically acts with Pdx1, Ngn3 and MafA to promote the expression of these genes, thereby improving GSID. However, the underlying mechanisms remain to be elucidated.
In conclusion, the present study demonstrated that the Pax4 gene was able to synergistically act with the transcription factors Pdx1, Ngn3 and MafA to convert HuMSCs to functional $\mathrm{p} \beta \mathrm{Cs}$. HuMSCs may be potential seed cells for generating functional $\mathrm{p} \beta \mathrm{Cs}$ for the therapy of diabetes.

\section{Acknowledgements}

Not applicable.

\section{Funding}

The present study was supported by the National Natural Science Foundation of China (grant no. 81671525 and 81070478), the Science and Technology Project from the Science Technology and Innovation Committee of Shenzhen Municipality (grant no. JCYJ20170817170110940) and the Sanming Project of Medicine in Shenzhen (grant no. SZSM201512033).

\section{Availability of data and materials}

All data generated or analyzed during the present study are included in this published article.

\section{Authors' contributions}

TZ, JS and LM designed the study and performed the experiments. TZ, HW, TW and JY collected the data. CW, HJ and SJ analyzed the data. TZ and HW prepared the manuscript. All authors read and approved the final manuscript.

\section{Ethics approval and consent to participate}

This study was approved by the ethics committees of Shanghai Children's Hospital (Shanghai, China) and of the Second Affiliated Hospital of Shantou University Medical College (Shantou, China). Written informed consent was obtained from the maternal donors and/or guardians.

\section{Patient consent for publication}

Not applicable.

\section{Competing interests}

The authors declare that they have no competing interests.

\section{References}

1. Stanekzai J, Isenovic ER and Mousa SA: Treatment options for diabetes: Potential role of stem cells. Diabetes Res Clin Pract 98: 361-368, 2012.

2. Bose B, Shenoy SP, Konda S and Wangikar P: Human embryonic stem cell differentiation into insulin secreting $\beta$-cells for diabetes. Cell Biol Int 36: 1013-1020, 2012.

3. Fujikawa T, Oh SH, Pi L, Hatch HM, Shupe T and Petersen BE: Teratoma formation leads to failure of treatment for type I diabetes using embryonic stem cell-derived insulin-producing cells. Am J Pathol 166: 1781-1791, 2005.

4. Wang H, Yang Y, Ho G, Lin X, Wu W, Li W, Lin L, Feng X, Huo X, Jiang J, et al: Programming of human umbilical cord mesenchymal stem cells in vitro to promote pancreatic gene expression. Mol Med Rep 8: 769-774, 2013. 
5. Friedman R, Betancur M, Boissel L, Tuncer H, Cetrulo C and Klingemann $\mathrm{H}$ : Umbilical cord mesenchymal stem cells: Adjuvants for human cell transplantation. Biol Blood Marrow Transplant 13: 1477-1486, 2007.

6. Sakamoto T, Ono H and Saito Y: Electron microscopic histochemical studies on the localization of hyaluronic acid in Wharton's jelly of the human umbilical cord. Nihon Sanka Fujinka Gakkai Zasshi 48: 501-507, 1996 (In Japanese).

7. Tsagias N, Koliakos I, Karagiannis V, Eleftheriadou M and Koliakos GG: Isolation of mesenchymal stem cells using the total length of umbilical cord for transplantation purposes. Transfus Med 21: 253-261, 2011.

8. Romanov YA, Svintsitskaya VA and Smirnov VN: Searching for alternative sources of postnatal human mesenchymal stem cells: Candidate MSC-like cells from umbilical cord. Stem Cells 21 $105-110,2003$

9. Kadivar M, Khatami S, Mortazavi Y, Shokrgozar MA, Taghikhani M and Soleimani M: In vitro cardiomyogenic potential of human umbilical vein-derived mesenchymal stem cells Biochem Biophys Res Commun 340: 639-647, 2006.

10. Ma L, Feng XY, Cui BL, Law F, Jiang XW, Yang LY, Xie QD and Huang TH: Human umbilical cord Wharton's Jelly-derived mesenchymal stem cells differentiation into nerve-like cells. Chin Med J (Engl) 118: 1987-1993, 2005.

11. Bao CS, Li XL, Liu L, Wang B, Yang FB and Chen LG: Transplantation of Human umbilical cord mesenchymal stem cells promotes functional recovery after spinal cord injury by blocking the expression of IL-7. Eur Rev Med Pharmacol Sci 22: 6436-6447, 2018.

12. Zhao Z, Chen Z, Zhao X, Pan F, Cai M, Wang T, Zhang H, Lu JR and Lei M: Sphingosine-1-phosphate promotes the differentiation of human umbilical cord mesenchymal stem cells into cardiomyocytes under the designated culturing conditions. J Biomed Sci 18: 37, 2011

13. Huang P, Lin LM, Wu XY, Tang QL, Feng XY, Lin GY, Lin X, Wang HW, Huang TH and Ma L: Differentiation of human umbilical cord Wharton's jelly-derived mesenchymal stem cells into germ-like cells in vitro. J Cell Biochem 109: 747-754, 2010.

14. Zhou Q and Melton DA: Extreme makeover: Converting one cell into another. Cell Stem Cell 3: 382-388, 2008.

15. Cavelti-Weder C, Zumsteg A, Li W and Zhou Q: Reprogramming of pancreatic Acinar cells to functional beta cells by in vivo transduction of a polycistronic construct containing Pdx1, Ngn3, MafA in mice. Curr Protoc Stem Cell Biol 40: A.10.1-4A.10.12, 2017.

16. Yamada T,Cavelti-Weder C,Caballero F, Lysy PA, GuoL, Sharma A, Li W, Zhou Q, Bonner-Weir S and Weir GC: Reprogramming mouse cells with a pancreatic duct phenotype to insulin-producing $\beta$-like cells. Endocrinology 156: 2029-2038, 2015.

17. Akinci E, Banga A, Tungatt K, Segal J, Eberhard D, Dutton JR and Slack JM: Reprogramming of various cell types to a beta-like state by Pdx1, Ngn3 and MafA. PLoS One 8: e82424, 2013.

18. Sosa-Pineda B, Chowdhury K, Torres M, Oliver G and Gruss P The Pax4 gene is essential for differentiation of insulin-producing beta cells in the mammalian pancreas. Nature 386: 399-402, 1997.

19. Druelle N, Vieira A, Shabro A, Courtney M, Mondin M, Rekima S Napolitano T, Silvano S, Navarro-Sanz S, Hadzic B, et al: Ectopic expression of Pax4 in pancreatic delta cells results in beta-like cell neogenesis. J Cell Biol 216: 4299-4311, 2017.

20. Zhang Y, Fava GE, Wang H, Mauvais-Jarvis F, Fonseca VA and $\mathrm{Wu} \mathrm{H}$ : PAX4 gene transfer induces $\alpha$-to- $\beta$ cell phenotypic conversion and confers therapeutic benefits for diabetes treatment. Mol Ther 24: 251-260, 2016.

21. Livak KJ and Schmittgen TD: Analysis of relative gene expression data using real-time quantitative PCR and the 2(-Delta Delta C (T)) method. Methods 25: 402-408, 2001.

22. Hald J, Sprinkel AE, Ray M, Serup P, Wright C and Madsen OD: Generation and characterization of Ptfla antiserum and localization of Ptf1a in relation to Nkx6.1 and Pdx1 during the earliest stages of mouse pancreas development. J Histochem Cytochem 56: 587-595, 2008

23. Ding L, Han L, Li Y, Zhao J, He P and Zhang W: Neurogenin 3 -directed cre deletion of Tsc1 gene causes pancreatic acinar carcinoma. Neoplasia 16: 909-917, 2014.
24. Babu DA, Chakrabarti SK, Garmey JC and Mirmira RG: Pdx1 and BETA2/NeuroD1 participate in a transcriptional complex that mediates short-range DNA looping at the insulin gene. J Biol Chem 283: 8164-8172, 2008 .

25. Wang J, Elghazi L, Parker SE, Kizilocak H, Asano M, Sussel L and Sosa-Pineda B: The concerted activities of Pax4 and Nkx2.2 are essential to initiate pancreatic beta-cell differentiation. Dev Biol 266: 178-189, 2004.

26. Ahlgren U, Jonsson $\mathrm{J}$ and Edlund $\mathrm{H}$ : The morphogenesis of the pancreatic mesenchyme is uncoupled from that of the pancreatic epithelium in IPF1/PDX1-deficient mice. Development 122: 1409-1416, 1996

27. Guz Y, Montminy MR, Stein R, Leonard J, Gamer LW, Wright CV and Teitelman G: Expression of murine STF-1, a putative insulin gene transcription factor, in beta cells of pancreas, duodenal epithelium and pancreatic exocrine and endocrine progenitors during ontogeny. Development 121: 11-18, 1995.

28. Gradwohl G, Dierich A, LeMeur M and Guillemot F: neurogenin3 is required for the development of the four endocrine cell lineages of the pancreas. Proc Natl Acad Sci USA 97: 1607-1611, 2000.

29. Kataoka K, Han SI, Shioda S, Hirai M, Nishizawa M and Handa H: MafA is a glucose-regulated and pancreatic beta-cell-specific transcriptional activator for the insulin gene. J Biol Chem 277: 49903-49910, 2002.

30. Sheets TP, Park KE, Park CH, Swift SM, Powell A, Donovan DM and Telugu BP: Targeted mutation of NGN3 gene disrupts pancreatic endocrine cell development in pigs. Sci Rep 8: 3582 , 2018.

31. Napolitano T, Avolio F, Courtney M, Vieira A, Druelle N, Ben-Othman N, Hadzic B, Navarro S and Collombat P: Pax4 acts as a key player in pancreas development and plasticity. Semin Cell Dev Biol 44: 107-114, 2015.

32. Lima MJ, Muir KR, Docherty HM, McGowan NW, Forbes S, Heremans Y, Heimberg H, Casey J and Docherty K: Generation of functional beta-like cells from human exocrine pancreas. PLoS One 11: e156204, 2016.

33. Collombat P, Hecksher-Sorensen J, Broccoli V, Krull J, Ponte I, Mundiger T, Smith J, Gruss P, Serup P and Mansouri A: The simultaneous loss of Arx and Pax4 genes promotes a somatostatin-producing cell fate specification at the expense of the alpha- and beta-cell lineages in the mouse endocrine pancreas. Development 132: 2969-2980, 2005.

34. Ray JD, Kener KB, Bitner BF, Wright BJ, Ballard MS, Barrett EJ, Hill JT, Moss LG and Tessem JS: Nkx6.1-mediated insulin secretion and $\beta$-cell proliferation is dependent on upregulation of c-Fos. FEBS Lett 590: 1791-1803, 2016.

35. Fueger PT, Schisler JC, Lu D, Babu DA, Mirmira RG, Newgard CB and Hohmeier HE: Trefoil factor 3 stimulates human and rodent pancreatic islet beta-cell replication with retention of function. Mol Endocrinol 22: 1251-1259, 2008.

36. Guillam MT, Dupraz P and Thorens B: Glucose uptake, utilization and signaling in GLUT2-null islets. Diabetes 49: 1485-1491, 2000.

37. Johnson JH, Ogawa A, Chen L, Orci L, Newgard CB, Alam T and Unger RH: Underexpression of beta cell high $\mathrm{Km}$ glucose transporters in noninsulin-dependent diabetes. Science 250: 546-549, 1990

38. Lu B, Kurmi K, Munoz-Gomez M, Jacobus Ambuludi EJ, Tonne JM, Rakshit K, Hitosugi T, Kudva YC, Matveyenko AV and Ikeda Y: Impaired $\beta$-cell glucokinase as an underlying mechanism in diet-induced diabetes. Dis Model Mech 11: pii: dmm033316, 2018

39. Vivoli M, Caulfield TR, Martinez-Mayorga K, Johnson AT, Jiao GS and Lindberg I: Inhibition of prohormone convertases $\mathrm{PC} 1 / 3$ and $\mathrm{PC} 2$ by 2,5 -dideoxystreptamine derivatives. Mol Pharmacol 81: 440-454, 2012.

This work is licensed under a Creative Commons Attribution-NonCommercial-NoDerivatives 4.0 International (CC BY-NC-ND 4.0) License. 